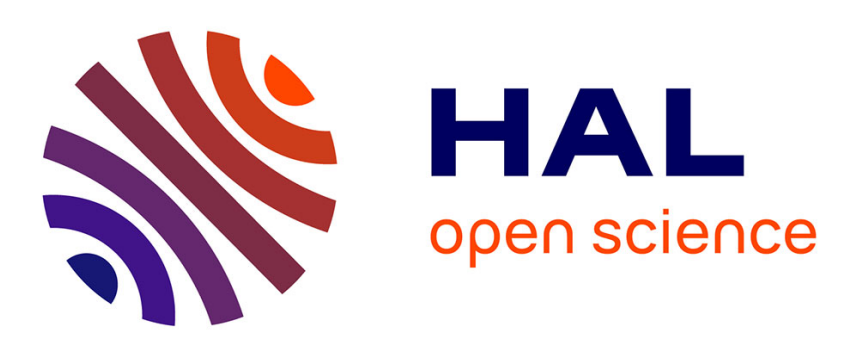

\title{
Oxygen reduction reaction features in neutral media on glassy carbon electrode functionalized by chemically prepared gold nanoparticles
}

Guillaume Gotti, David Evrard, Katia Fajerwerg, Pierre Gros

\section{- To cite this version:}

Guillaume Gotti, David Evrard, Katia Fajerwerg, Pierre Gros. Oxygen reduction reaction features in neutral media on glassy carbon electrode functionalized by chemically prepared gold nanoparticles. Journal of Solid State Electrochemistry, 2016, 20 (6), pp.1539-1550. 10.1007/s10008-016-3159-x . hal-01360006

\section{HAL Id: hal-01360006 https://hal.science/hal-01360006}

Submitted on 5 Sep 2016

HAL is a multi-disciplinary open access archive for the deposit and dissemination of scientific research documents, whether they are published or not. The documents may come from teaching and research institutions in France or abroad, or from public or private research centers.
L'archive ouverte pluridisciplinaire HAL, est destinée au dépôt et à la diffusion de documents scientifiques de niveau recherche, publiés ou non, émanant des établissements d'enseignement et de recherche français ou étrangers, des laboratoires publics ou privés. 


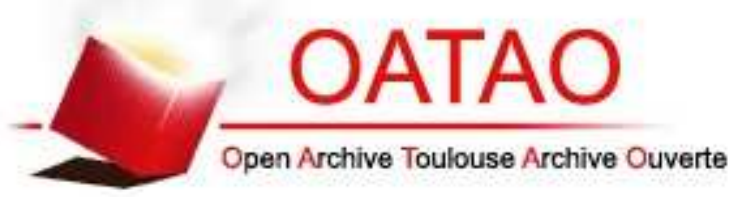

\section{Open Archive TOULOUSE Archive Ouverte (OATAO)}

OATAO is an open access repository that collects the work of Toulouse researchers and makes it freely available over the web where possible.

This is an author-deposited version published in : http://oatao.univ-toulouse.fr/ Eprints ID : 15837

To link to this article : DOI : 10.1007/s10008-016-3159-x URL : http://dx.doi.org/10.1007/s10008-016-3159-x

To cite this version : Gotti, Guillaume and Evrard, David and Fajerwerg, Katia and Gros, Pierre Oxygen reduction reaction features in neutral media on glassy carbon electrode functionalized by chemically prepared gold nanoparticles. (2016) Journal of Solid State Electrochemistry, vol. 20. pp. 1539-1550. ISSN 1432-8488

Any correspondence concerning this service should be sent to the repository administrator: staff-oatao@ listes-diff.inp-toulouse.fr 


\title{
Oxygen reduction reaction features in neutral media on glassy carbon electrode functionalized by chemically prepared gold nanoparticles
}

\author{
Guillaume Gotti $^{1,2,3,4}$ - David Evrard ${ }^{1,2} \cdot$ Katia Fajerwerg $^{3,4} \cdot$ Pierre Gros $^{1,2}$
}

\begin{abstract}
Gold nanoparticles (AuNPs) were prepared by chemical route using four different protocols by varying reducer, stabilizing agent, and solvent mixture. The obtained AuNPs were characterized by transmission electronic microscopy (TEM), UV-visible, and zeta potential measurements. From these latter, surface charge densities $\sigma$ were calculated to evidence the effect of the solvent mixture on AuNP stability. The AuNPs were then deposited onto glassy carbon (GC) electrodes by drop casting, and the resulting deposits were characterized by cyclic voltammetry $(\mathrm{CV})$ in $\mathrm{H}_{2} \mathrm{SO}_{4}$ and field emission gun scanning electron microscopy (FEG-SEM). The electrochemical kinetic parameters of the four different modified electrodes toward oxygen reduction reaction (ORR) in neutral $\mathrm{NaCl}-\mathrm{NaHCO}_{3}$ media $(0.15 \mathrm{M} / 0.028 \mathrm{M}, \mathrm{pH} 7.4)$ were evaluated by rotating disk electrode voltammetry and subsequent Koutecky-Levich treatment. Contrary to what we previously obtained with electrodeposited AuNPs [Gotti et al., Electrochim. Acta 2014], the highest cathodic transfer coefficients $\beta$ were not obtained on the smallest particles, highlighting the influence of the stabilizing ligand together with the deposit morphology on the ORR kinetics.
\end{abstract}

David Evrard

evrard@chimie.ups-tlse.fr

1 Université de Toulouse, UPS, INPT, Laboratoire de Génie Chimique, 118 route de Narbonne, 31062 Toulouse, France

2 CNRS, Laboratoire de Génie Chimique, 31062 Toulouse, France

3 CNRS, LCC (Laboratoire de Chimie de Coordination), 205 route de Narbonne, 31077 Toulouse, France

4 Université de Toulouse, UPS, INPT, LCC, 31077 Toulouse, France
Keywords Chemically prepared gold nanoparticles · Modified glassy carbon electrode - Oxygen reduction reaction · Neutral media $\cdot$ Koutecky-Levich analysis · Electrochemical kinetics $\cdot$ Cathodic transfer coefficient $\cdot$ Stabilizing ligand influence

\section{Introduction}

Oxygen reduction reaction (ORR) has gained a standing interest in the last 20 years as a result of the wide range of applications that it is involved in, such as chemical and biochemical analysis, pharmaceutics, corrosion, energy conversion, and fuel cells [1]. It has been, for a long time, one of the most studied redox processes, both from mechanistic $[2,3]$ and kinetic [4-6] aspects. Indeed, several different mechanisms may be invoked to account for $\mathrm{O}_{2}$ reduction, the most commonly reported being either a four-electron "direct" pathway (Reaction 1) [7] or a succession of two bielectronic steps involving hydrogen peroxide $\left(\mathrm{H}_{2} \mathrm{O}_{2}\right)$ as an intermediate species (Reactions 2 and 3) [8-10]:

$$
\begin{aligned}
& \mathrm{O}_{2}+4 \mathrm{H}^{+}+4 \mathrm{e}^{-} \rightarrow 2 \mathrm{H}_{2} \mathrm{O} \quad \mathrm{E}^{\circ}=1.23 \mathrm{~V} / \mathrm{SHE} \\
& \mathrm{O}_{2}+2 \mathrm{H}^{+}+2 \mathrm{e}^{-} \rightarrow \mathrm{H}_{2} \mathrm{O} 2 \quad \mathrm{E}^{\circ}=0.70 \mathrm{~V} / \mathrm{SHE} \\
& \mathrm{H}_{2} \mathrm{O}_{2}+2 \mathrm{H}^{+}+2 \mathrm{e}^{-} \rightarrow \mathrm{H}_{2} \mathrm{O} \quad \mathrm{E}^{\circ}=1.78 \mathrm{~V} / \mathrm{SHE}
\end{aligned}
$$

The main parameters that impact on mechanistic pathway are the operating media and electrode materials [8], and some authors have reported more complex reduction paths on alloys and noble metals [11]. Among these latter, gold ( $\mathrm{Au})$ in its nanosized particle form exhibits a very good catalytic activity $[12,13]$. Au nanoparticles (AuNPs) may be prepared either by electrochemical methods [14-16] or by chemical routes [17, 18]. In both cases, it is possible to tailor the nanoparticle (NP) 
shape and size, which is of particular interest for catalytic properties toward ORR [19, 20]. For instance, it has been reported that icosahedral AuNPs showed enhanced electrocatalytic performances with respect to ORR due to their multipletwinned structure which exhibited high surface defect density [21]. In the same trend, the group of Feliu has reported a particularly high reactivity of cubic AuNPs toward ORR [22]. With respect to NP size, Inasaki et al. showed that small AuNPs (ca. $3 \mathrm{~nm}$ ) induced direct four-electron reduction of $\mathrm{O}_{2}$ at low overpotential whereas NPs higher than 10-15 nm behaved much more like bulk $\mathrm{Au}$, inducing two successive bielectronic steps [23]. ORR on AuNPs is also reported to be crystal structure-dependent, $\mathrm{Au}(100)$ facets $[24,25]$ and Au(100)-like [26] NPs being known to favor its kinetics. Wain has confirmed by scanning electrochemical microscopy (SECM) that AuNP electrocatalytic activity toward ORR increased with decreasing particle diameter and has suggested this was correlated to the $\mathrm{Au}(110) / \mathrm{Au}(111)$ site ratio [27].

As a consequence of the leading applications it may be dedicated to, ORR has been extensively studied in acidic and basic media. Many papers in the literature have reported a remarkable $\mathrm{pH}$ effect on the kinetic and the mechanism of the ORR on Au-based electrodes [28-30]. Indeed, ORR on Au materials exhibits a higher rate in alkaline than in acidic media as the consequence of favored kinetics of the reactions involving the superoxide anion $\mathrm{O}_{2}{ }^{-}$that follow the transfer of the first electron [31, 32]. In both media, electrochemical techniques such as cyclic voltammetry [33, 34], impedance spectroscopy [35], rotating disk [36, 37], and ring disk electrode $[24,38]$ and SECM experiments [27] have allowed kinetic features to be reached. Surprisingly, very few works dealing with ORR on AuNPs in neutral media have been reported in the literature [39-41] although it would be of great interest for applications such as environmental survey [42] or clinical analysis [43]. Raj et al. have reported a qualitative work highlighting the electrocatalytic effect of chemically prepared AuNPs stabilized by various organic ligands [40]. For instance, it was shown that in the case of cystamine as the stabilizing agent, $\mathrm{O}_{2}$ reduction into $\mathrm{H}_{2} \mathrm{O}_{2}$ occurred at a potential $130 \mathrm{mV}$ less cathodic than on bulk Au. Shim et al. have compared the ORR kinetics on chemically prepared AuNPs and on bulk $\mathrm{Au}$, but their work was limited to the determination of the number of electrons exchanged [41]. Among these scarce studies, only El-Deab et al. have conducted a more detailed kinetic investigation but did not go as far as the determination of kinetic parameters such as cathodic transfer coefficients $\beta$ [39]. In order to fill this lack for kinetic data upon ORR in neutral media, we have recently reported a complete study dealing with AuNPs electrodeposited on glassy carbon (GC) [44] and compared their performances to those previously obtained on unmodified $\mathrm{GC}$ and bulk $\mathrm{Au}$ in the same media [45]. By using several deposits prepared by constant potential electrolysis with different sets of parameters, namely deposition potential and electrolysis duration, a correlation has been evidenced between AuNP size and density and their performances toward ORR. Indeed, the best results have been obtained with the deposits which exhibited a high density $\left(555 \pm 49 \mu^{-2}\right)$ of relatively small AuNPs $(25 \pm 12 \mathrm{~nm})$, i.e., the deposits prepared using the most cathodic potential and the longest electrolysis duration. In this latter case, the AuNPs-GC electrode exhibited significantly enhanced kinetics for ORR with a $\beta$ value $0.61 \pm 0.03$ much higher than that obtained on bulk Au and on unmodified GC ( $0.39 \pm 0.02$ and $0.24 \pm 0.02$, respectively). In this paper, we extend our kinetic investigation to chemically prepared AuNPs. In order to get several distributions of relatively small NPs, the syntheses were performed using different combinations of reducing and stabilizing agents and solvent. The corresponding AuNPs were characterized using transmission electronic microscopy (TEM), UV-visible, and zeta potential measurements and then deposited onto GC electrodes by drop casting. The resulting deposits were characterized by cyclic voltammetry $(\mathrm{CV})$ in $\mathrm{H}_{2} \mathrm{SO}_{4}$ and field emission gun scanning electron microscopy (FEG-SEM) and their performances toward ORR in neutral $\mathrm{NaCl}-\mathrm{NaHCO}_{3}$ media $(0.15 \mathrm{M} / 0.028 \mathrm{M}, \mathrm{pH} 7.4)$ evaluated by rotating disk electrode voltammetry and subsequent Koutecky-Levich treatment. In particular, the cathodic transfer coefficients $\beta$ were determined for each AuNPs-GC electrode and their values were compared to those previously obtained in the same conditions on bulk materials and electrodeposited AuNPs.

\section{Experimental}

\section{Chemicals and apparatus}

Unless otherwise stated, all the experiments were performed at the Laboratoire de Génie Chimique (LGC) (Toulouse, France). All the solutions were prepared using ultra pure water (Milli-Q Millipore, $18.2 \mathrm{M} \Omega \mathrm{cm}$ ). Ninety-six percent ethanol (ACS reagent) was from Fluka. $\mathrm{HAuCl}_{4} \cdot 3 \mathrm{H}_{2} \mathrm{O}$ (pro analysis grade) was purchased from Acros Organics. Ninety-five percent $\mathrm{H}_{2} \mathrm{SO}_{4}$ (Normapur grade) and $37 \% \mathrm{HCl}$ were supplied by VWR Prolabo. $N$-acetyl-L-cystein $\left(\mathrm{C}_{5} \mathrm{H}_{9} \mathrm{NSO}_{3}, \mathrm{NAC}\right)$ (Sigma-Grade) was purchased from Sigma-Aldrich. $\mathrm{NaCl}$ and $\mathrm{NaHCO}_{3}$ (analytical grade) were from Fisher Scientific. Trisodium citrate $\left(\mathrm{C}_{6} \mathrm{H}_{5} \mathrm{Na}_{3} \mathrm{O}_{7}\right)$ anhydrous and $98 \%$ sodium borohydride $\left(\mathrm{NaBH}_{4}\right)$ were purchased from Alfa Aesar.

Except the electrode activation which was performed at room temperature, all the electrochemical experiments were performed at controlled temperature $\left(20{ }^{\circ} \mathrm{C}\right)$ using a Fisher Scientific Isotemp thermoregulator.

All the electrochemical experiments were carried out in a standard three-electrode water-jacketed cell using a $\mu$-Autolab II potentiostat (Metrohm) interfaced to a personal computer 
controlled with NOVA 1.10 software package (Metrohm). A Metrohm $\mathrm{Ag} / \mathrm{AgCl} / \mathrm{KCl} 3 \mathrm{M}$ electrode, separated from the electrochemical cell by a Teflon PTFE capillary containing the supporting electrolyte solution and terminated by a ceramic diaphragm (D type), and a Metrohm glassy carbon (GC) wire were used as reference and counter electrodes, respectively. All the potentials given in the text and the figures are referred to this reference. Working electrodes were GC plates from OrigaLys ElectroChem SAS (diameter $=5.5 \mathrm{~mm}$, $A=0.24 \mathrm{~cm}^{2}$ ). The geometrical surface area $A$ was used to calculate current densities. When necessary, working electrodes were rotated using a rotating system Model EDI 101 interfaced with a CTV 101 speed control unit from Radiometer.

Unless otherwise stated, the solutions were deaerated using a $\mathrm{N}_{2}$ stream for $15 \mathrm{~min}$. $\mathrm{A} \mathrm{N}_{2}$ atmosphere was also maintained over the solution during the corresponding experiments.

\section{AuNP synthesis}

Four different synthesis ways were used to produce sizedefined AuNPs through chemical reduction. For the sake of clarity, these syntheses were named A, B, C, and D and the corresponding AuNPs designed as $\operatorname{AuNPs}(\mathrm{X})$ with $\mathrm{X}=\mathrm{A}, \mathrm{B}$, $\mathrm{C}$, and $\mathrm{D}$, respectively, all along the text.

Synthesis A

According to the classical method described by Turkevich [46] and refined by Frens [47], $22 \mathrm{mg}\left(8.5 \times 10^{-5} \mathrm{~mol}\right)$ of sodium citrate was dissolved in $30 \mathrm{~mL}$ of Milli-Q water. The solution was heated under reflux, and $20 \mathrm{~mL}$ of an aqueous solution of $\mathrm{HAuCl}_{4}\left(9.9 \mathrm{mg}, 2.5 \times 10^{-5} \mathrm{~mol}\right.$, ratio 3.4) was quickly added. The mixture was kept under reflux for $20 \mathrm{~min}$ and then cooled to room temperature to afford a ruby red solution.

\section{Synthesis B}

This synthesis was performed using exactly the same procedure as for synthesis A except that all reagents were dissolved in a 50/50 volume ratio $\mathrm{H}_{2} \mathrm{O}$ /ethanol mixture.

Synthesis C

In a similar way to synthesis $\mathrm{A}, 22 \mathrm{mg}\left(8.5 \times 10^{-5} \mathrm{~mol}\right)$ of sodium citrate was dissolved in $30 \mathrm{~mL}$ of Milli-Q water. The solution was heated under reflux, and $20 \mathrm{~mL}$ of an aqueous solution of $\mathrm{HAuCl}_{4}\left(9.9 \mathrm{mg}, 2.5 \times 10^{-5} \mathrm{~mol}\right.$, ratio 3.4) was quickly added. After 20 -min reflux, $14 \mathrm{mg}\left(8.5 \times 10^{-5} \mathrm{~mol}\right)$ of NAC was added to the mixture. Immediately after this last addition, the reflux was stopped and the mixture allowed to cool down to room temperature to afford a ruby red solution.

Synthesis D

In $30 \mathrm{~mL}$ of Milli-Q water at room temperature, $3.2 \mathrm{mg}$ $\left(8.5 \times 10^{-5} \mathrm{~mol}\right)$ of $\mathrm{NaBH}_{4}$ was dissolved. Twenty milliliters of an aqueous solution of $\mathrm{HAuCl}_{4}\left(9.9 \mathrm{mg}, 2.5 \times 10^{-5} \mathrm{~mol}\right.$, ratio 3.4) was added. Immediately after this addition, $14 \mathrm{mg}$ $\left(8.5 \times 10^{-5} \mathrm{~mol}\right)$ of NAC was quickly added and the resulting mixture was stirred at room temperature for $20 \mathrm{~min}$ to afford a very dark ruby red solution.

\section{Electrode preparation and modification}

All the working electrodes were carefully polished prior to use. They were first polished by silicon carbide grinding paper (grit 1200) for $10 \mathrm{~s}$. GC surfaces were further polished successively by a 9-, 3-, 1-, and 0.25- $\mu \mathrm{m}$ diamond suspension (Presi) on a cloth polishing pad during $2 \mathrm{~min}$ for each size. Between each polishing step, the surfaces were cleaned with Milli-Q water. Finally, the electrodes were rinsed in an ultrasonic $96 \%$ ethanol bath (three times for $10 \mathrm{~min}$ ) and cleaned with Milli-Q water. After drying, the quality of the polishing step was verified by checking the surface state using a Nikon Eclipse LV150 optical microscope.

Electrode functionalization was achieved by using the drop casting technique. Briefly, $50 \mu \mathrm{L}$ of AuNP solution A, B, C, or $\mathrm{D}$ was dropped on GC plates and slowly evaporated at room temperature overnight. The resulting modified electrode was then dried in an oven at $60{ }^{\circ} \mathrm{C}$ for $1 \mathrm{~h}$ in order to remove solvent traces. In such conditions, the loading of Au catalyst was $21 \mu \mathrm{g} \mathrm{cm}^{-2}$.

Prior to ORR measurements, the AuNPs-GC electrodes were carefully rinsed using Milli-Q water and activated in a deaerated $0.5 \mathrm{~mol} \mathrm{~L}^{-1} \mathrm{H}_{2} \mathrm{SO}_{4}$ solution by running 30 scans between 0 and $1.4 \mathrm{~V}$ at a scan rate of $100 \mathrm{mV} \mathrm{s}^{-1}$.

\section{AuNP characterization}

AuNPs were characterized by transmission electron microscopy (TEM) at the Centre de Microscopie Electronique Appliquée à la Biologie (CMEAB, Toulouse) using a HT 7700 Hitachi equipment with an accelerating voltage of $80 \mathrm{kV}$. Average diameter measurements were carried out by micrograph analysis with Origin 8, using around 100 NPs for each sample.

The determination of the surface Plasmon band was achieved by recording UV-visible spectra using a HewlettPackard 8452A diode array spectrophotometer.

Zeta potential measurements were recorded on a Malvern Zetasizer Nanoseries ZS90 controlled by integrated software. Calculations were performed using the Smoluchowski model [48, 49].

The AuNPs-GC surface was characterized by field emission gun scanning electron microscopy (FEG-SEM) at the CMEAB using Quanta 250 FEG FEI equipment with an accelerating voltage of $5 \mathrm{kV}$ and a working distance between 3 and $8 \mathrm{~mm}$ depending on the sample. Image analysis was carried out using a LGC homemade program for particle counting (density estimation) and average diameter measurement developed using MATLAB image processing toolbox software. 


\section{Oxygen reduction}

Electrochemical reduction of $\mathrm{O}_{2}$ on $\operatorname{AuNPs}(\mathrm{X})(\mathrm{X}=\mathrm{A}, \mathrm{B}, \mathrm{C}$, D)-modified electrodes was performed at $20{ }^{\circ} \mathrm{C}$ in an aerated $\mathrm{NaCl}-\mathrm{NaHCO}_{3}\left(0.15 / 0.028 \mathrm{~mol} \mathrm{~L}^{-1} \mathrm{pH} 7.4\right)$ solution by using linear sweep voltammetry and different electrode rotation rates (from 600 to $2600 \mathrm{rpm}$ ). The potential was swept from the open circuit potential (ocp) to that corresponding to hydrogen evolution at a scan rate of $1 \mathrm{mV} \mathrm{s}^{-1}$ in order to ensure steady-state conditions.

\section{Results and discussion}

\section{Gold NP synthesis and characterization}

In order to get different size-defined gold nanoparticles (AuNPs) through chemical reduction, four synthetic routes were explored and the resulting AuNPs were characterized by UV-visible, zeta potential measurements, and TEM (Fig. 1). Table 1 summarizes all the corresponding data. Synthesis A corresponds to the classical Turkevich method [46], in which sodium citrate acts both as reducing and as stabilizing agent. TEM micrograph analysis showed that AuNPs(A) exhibited an average size $18 \pm 4 \mathrm{~nm}$, although the distribution was not perfectly Gaussian (Fig. 1a). This result is consistent with literature data for this synthesis $[46,50]$. As a result of very close experimental conditions (the only difference being the solvent mixture), $\operatorname{AuNPs}(\mathrm{B})$ were found to exhibit similar average size to AuNPs(A), ca. $23 \pm 6 \mathrm{~nm}$, the Gaussian feature of the distribution being much more evident in this case (Fig. 1b), indicating more monodisperse AuNPs. $\operatorname{AuNPs}(C)$ were rather smaller than the NPs prepared by using the former two syntheses with an average size $10 \pm 1 \mathrm{~nm}$ (Fig. 1c), in accordance with a strong interaction between $\mathrm{Au}$ and the $\mathrm{S}$ atom of NAC which may favor small NP stabilization [51]. Finally, AuNPs(D) were smaller again ca. $2 \pm 1 \mathrm{~nm}$ (Fig. 1d), as a result of the combined effect of NAC and the use of a strong reducing agent, namely $\mathrm{NaBH}_{4}$. The average size obtained for AuNPs(D) was consistent with recently reported data [52]. However, it has to be noticed that in this latter work, the synthesis procedure used implied mixtures of solvents and cooling to $0{ }^{\circ} \mathrm{C}$ (in fact, a variation of the Brust-Schiffrin synthesis); i.e., it was actually much more complicated than synthesis D which was achieved in water at room temperature. UV-visible spectra recorded for each kind of AuNPs (not shown) clearly showed the surface Plasmon band and the classical red shifts observed while increasing NP size (see Table 1 for quantitative features) [53]. Zeta potential measurements were also performed. Except for $\operatorname{AuNPs}(\mathrm{B})$, the trend was the bigger the NPs, the lower the zeta potential value (Table 1). Such a trend has already been observed by Majzik et al. [54] and Brewer et al. [55] for citrate- stabilized AuNPs. It has to be noticed that AuNPs(D), the size of which was that of nanoclusters rather than of NPs [56], exhibited a value close to that considered as the limit ensuring a colloidal system stability (ca. $-30 \mathrm{mV}$ ) $[57,58]$. Surprisingly, AuNPs(B) also exhibited such a value, ca. $\zeta=-28 \mathrm{mV}$, indicating an unstable colloidal system despite that the corresponding NP size was similar to that of AuNPs(A) which exhibited $\zeta=-46 \mathrm{mV}$. The only difference between both syntheses was the solvent used, since synthesis $\mathrm{B}$ was achieved in a 50/50 volume ratio $\mathrm{H}_{2} \mathrm{O}$ / ethanol mixture instead of $\mathrm{H}_{2} \mathrm{O}$ in the case of the classical Turkevich protocol (synthesis A). Since the $\zeta$ value depends on both the surface charge of the particles and the medium used for the measurement, further information was needed to evaluate whether or not the difference in $\zeta$ values between AuNPs(A) and AuNPs(B) was only due to the different medium used for the measurements. It thus became necessary to develop supplementary considerations in order to extract the contribution of the particle charge from that of the measurement medium. To better understand our results, surface charge densities $\sigma$ were calculated for $\operatorname{AuNPs}(\mathrm{A})$ and $\operatorname{AuNPs}(\mathrm{B})$. First, it was assumed that the zeta potential was equivalent to the surface potential $\psi$. The dimensionless surface potential $\tilde{\psi}$ was calculated using Eq. (1):

$$
\tilde{\psi}=\psi \frac{e}{k T}
$$

where $e$ is the elementary charge $\left(1.6 \times 10^{-19} \mathrm{C}\right), k$ is the Boltzmann constant $\left(1.38 \times 10^{-23} \mathrm{~m}^{2} \mathrm{~kg} \mathrm{~s}^{-2} \mathrm{~K}^{-1}\right)$, and $T$ is the temperature $(\mathrm{K})$. From $\tilde{\psi}$, the dimensionless surface charge density $\tilde{\psi}$ was accessed using Eq. (2):

$\tilde{\sigma}=\tilde{\psi}\left(\frac{\kappa \mathrm{a}+1}{\kappa \mathrm{a}}\right)$

where $a$ is the NP radius (m) and $\kappa$ is the inverse of the Debye length and may be expressed as follows:

$\kappa=\sqrt{\frac{2 n_{0} e^{2}}{\varepsilon \mathrm{kT}}}$

where $n_{0}$ is the number density of the electrolyte $\left(\mathrm{m}^{-3}\right)$ and $\varepsilon$ is the dielectric permittivity $\left(\mathrm{F} \mathrm{m}^{-1}\right)$. For $\varepsilon$ calculation, it was used $\varepsilon_{0}=8.85 \times 10^{-12} \mathrm{~F} \mathrm{~m}^{-1}$ and the corresponding dielectric constant $\varepsilon_{\mathrm{r}}$ for water (78.5) and the $50 / 50$ volume ratio $\mathrm{H}_{2} \mathrm{O}$ / ethanol mixture (53.2) [59]. Finally, the surface charge density $\sigma$ was obtained from $\tilde{\psi}$ using the following expression (Eq. (4)):

$\sigma=\tilde{\sigma} \sqrt{2 n_{0}} \varepsilon \mathrm{kT}$ 
Fig. 1 TEM micrographs and size distribution of AuNPs prepared using the following synthesis: a A, b B, c C, and $\mathbf{d} \mathrm{D}$
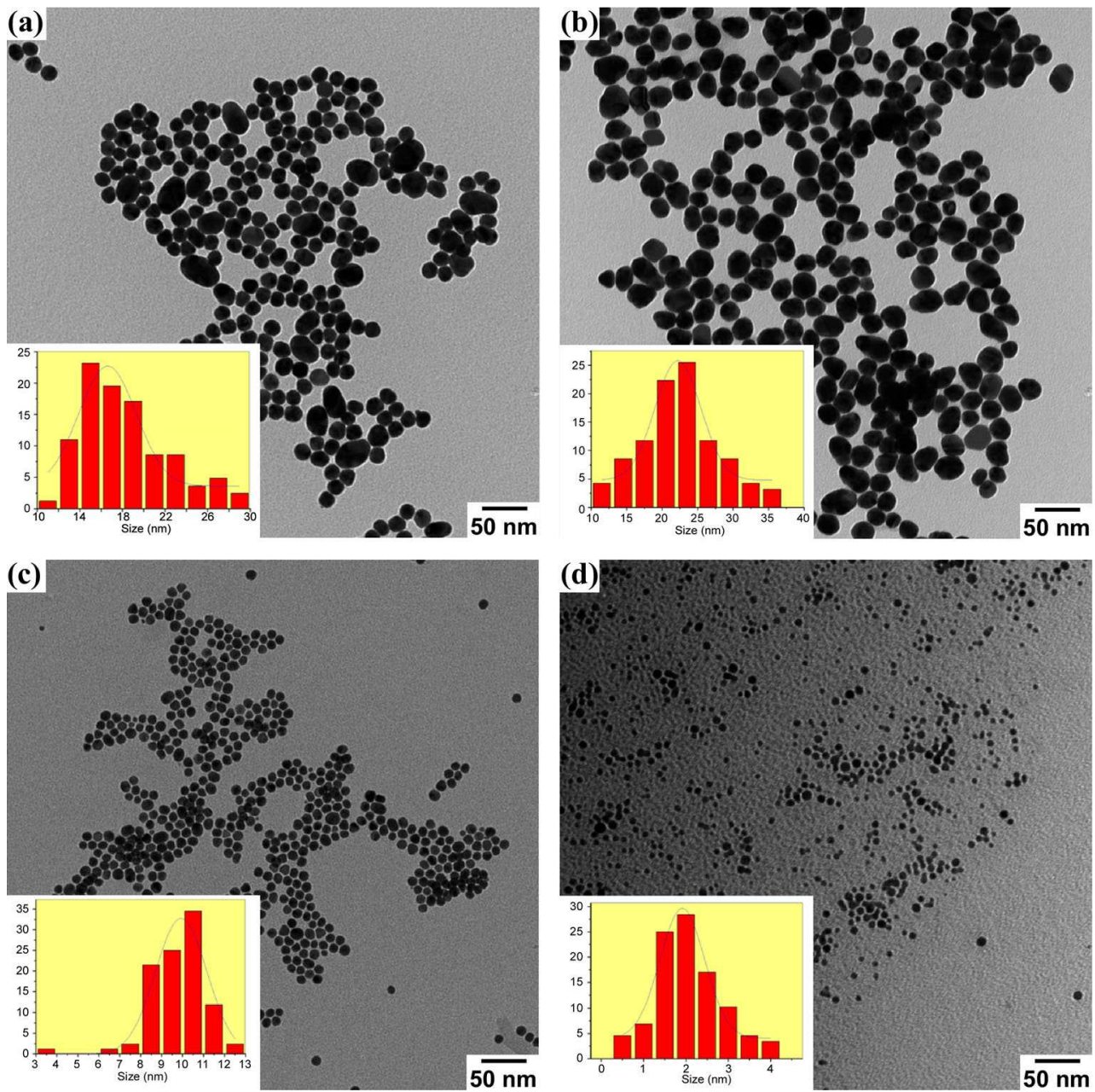

Here, the surface charge densities found were $\sigma_{\mathrm{A}}=-11.2 \mathrm{mC} \mathrm{m}^{-2}$ and $\sigma_{\mathrm{B}}=-4.9 \mathrm{mC} \mathrm{m}^{-2}$ for AuNPs(A) and $\operatorname{AuNPs}(\mathrm{B})$, respectively. For AuNPs(A) which were prepared in water, the value of $\sigma$ was nearly 2.3 times more negative than for $\mathrm{AuNPs}(\mathrm{B})$ which were prepared in a 50/50 volume ratio $\mathrm{H}_{2} \mathrm{O}$ /ethanol mixture, suggesting that more citrate ligands surrounded the NPs in the former medium, thus leading to more stable colloids. Thus, the difference in $\zeta$ values observed between $\operatorname{AuNPs}(\mathrm{A})$ and $\operatorname{AuNPs}(\mathrm{B})$ was not only due to the different media used for the $\zeta$ potential measurements since the nature of the solvent used for the synthesis clearly influenced the surface charge density of the resulting NPs.

\section{AuNP deposition onto GC and deposit characterization}

AuNPs were deposited by simple drop casting technique (see "Experimental" section for detail). The resulting deposits were characterized using FEG-SEM (Fig. 2). The corresponding micrographs exhibited clear differences in terms of NP
Table 1 Physicochemical characteristics of colloidal AuNPs and their corresponding deposits onto GC

\begin{tabular}{llllll}
\hline Synthesis & Mean size $(\mathrm{nm})$ & SPB $(\mathrm{nm})$ & Zeta potential $\zeta(\mathrm{mV})$ & $Q_{\text {oxides }}(\mu \mathrm{C})^{\mathrm{a}}$ & $\beta$ \\
\hline A & $18 \pm 4$ & 520 & -46 & 6.9 & $0.59 \pm 0.04$ \\
B & $23 \pm 6$ & 526 & -28 & 4.2 & $0.17 \pm 0.12$ \\
C & $10 \pm 1$ & 518 & -38 & 0.8 & $0.28 \pm 0.02$ \\
D & $2 \pm 1$ & 510 & -30 & 11.9 & $0.55 \pm 0.04$ \\
\hline
\end{tabular}

$S P B$ surface Plasmon band

${ }^{a} Q_{\text {oxides }}$ is the charge corresponding to the reduction of $\mathrm{Au}$ oxides formed during the forward scan of cyclic voltammetry recorded in $0.5 \mathrm{M} \mathrm{H}_{2} \mathrm{SO}_{4}$ between 0 and $1.4 \mathrm{~V}$ on each $\mathrm{AuNPs}(\mathrm{X})(\mathrm{X}=\mathrm{A}, \mathrm{B}, \mathrm{C}, \mathrm{D})$ deposited by drop casting onto GC electrode surfaces 
Fig. 2 FEG-SEM images of AuNPs drop casted onto GC electrode surface. AuNPs prepared using the following synthesis: a A, b B, c C, and d D
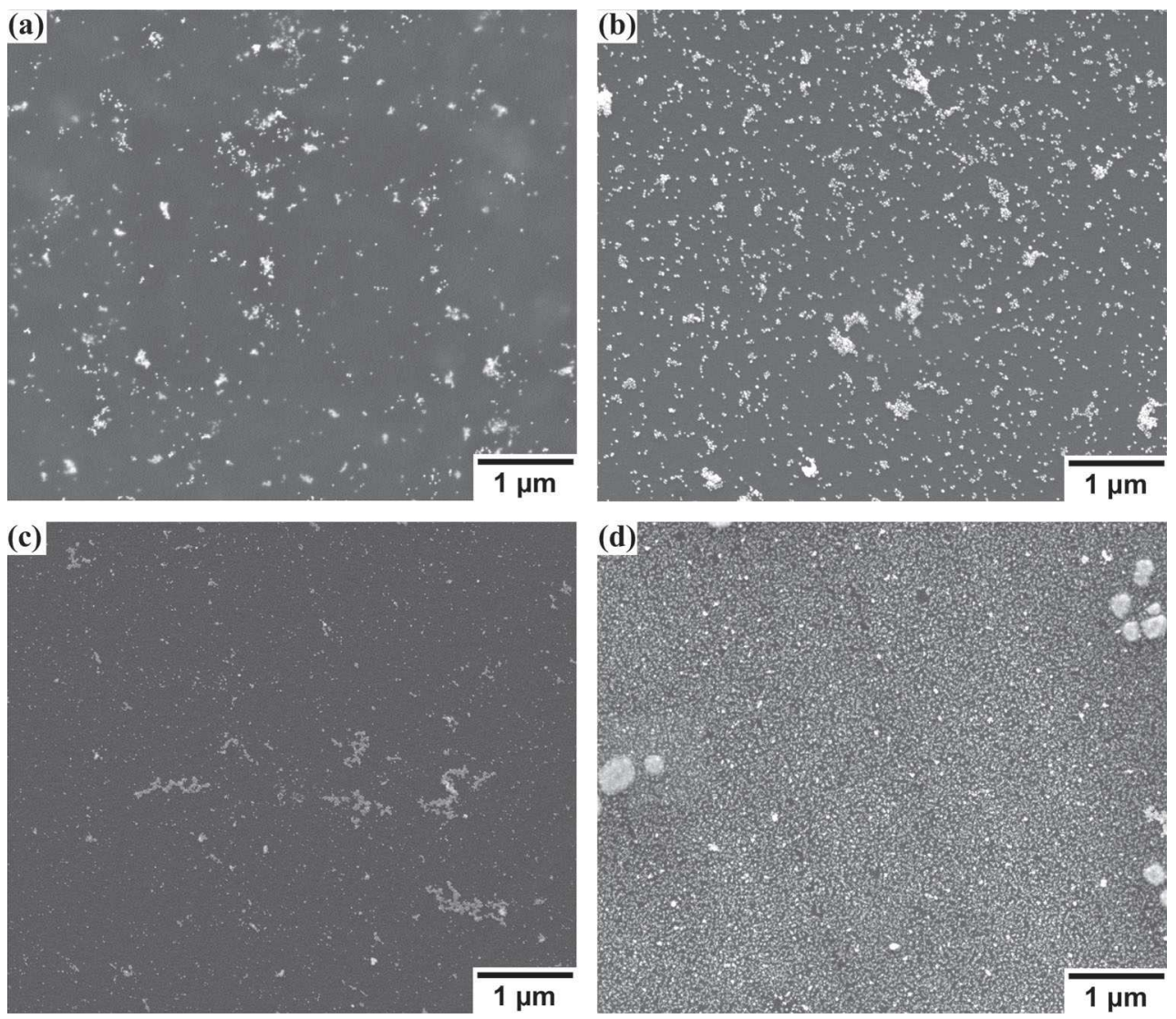

coverage and density. Indeed, Fig. 2a-c shows very sparse deposits for AuNPs(A), (B), and (C), respectively, in which big aggregates of NPs may be observed. Due to this lack of homogeneity in NP coverage over the GC surface, providing a value for NP density would be meaningless. On the contrary, a very dense, homogeneous deposit was observed for AuNPs(D) (Fig. 2d). In this case, the NP density onto GC was found $318 \mu^{-2}$. However, the density was clearly underestimated due to the fact that our homemade automatic counting software did not exhibit sufficient resolution to properly separate such very small AuNPs. It has to be noticed that the big, white aggregates that may be observed on both sides of Fig. $2 \mathrm{~d}$ corresponded to $\mathrm{NaCl}$ crystals. Comparison between Fig. 2a, 2b showed that AuNP drop casting onto GC was favored by the $\mathrm{H}_{2} \mathrm{O}$ /ethanol mixture used for the NP preparation (synthesis $\mathrm{B}$ ), probably because the presence of alcohol fastened solvent evaporation, resulting in a denser and more homogeneous deposit. However and consistently with the less negative surface charge density of AuNPs(B), more numerous and bigger aggregates were observed compared to the deposit obtained with AuNPs(A). Surprisingly, Fig. 2c which corresponded to $\operatorname{AuNPs}(\mathrm{C})$ prepared using NAC as a ligand did not show a more homogeneous deposit than Fig. $2 \mathrm{a}, 2 \mathrm{~b}$, as could be expected due to the stabilizing properties of NAC. In this case, $\operatorname{AuNPs}(\mathrm{C})$ were very scarce on the GC surface, although some aggregates were observed.
The reason for such a surprising result remains unclear. It has to be noticed that the same experiment was repeated several times using AuNPs from same and different syntheses $\mathrm{C}$ and always afforded similar deposit morphologies. Finally, the best deposit, both in terms of homogeneity and density, corresponded to the smallest AuNPs which were prepared using $\mathrm{NaBH}_{4}$ as the reducer and NAC (synthesis D). It has to be noticed that $\operatorname{AuNPs}(\mathrm{D})$ deposit is the one which compared the most favorably with the deposits obtained by electrodeposition using constant potential electrolysis (CPE) [44] in terms of density. Indeed, it was reported that CPE at $-0.3 \mathrm{~V}$ for $1800 \mathrm{~s}$ afforded a dense deposit of

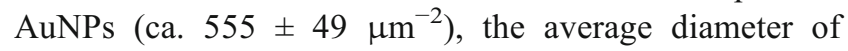
which was $25 \pm 12 \mathrm{~nm}$.

$\operatorname{AuNPs}(\mathrm{X})$-GC electrodes (X = A, B, C, D) were then activated and characterized by recording 30 consecutive cyclic voltammetry $(\mathrm{CV})$ scans in $0.5-\mathrm{M} \mathrm{H}_{2} \mathrm{SO}_{4}$ solution. Figure 3 depicts the last of these 30 scans for each deposit. The corresponding voltammograms were presented in terms of current density in order to make the comparison between all four deposits easier. However, it was not possible to normalize the CVs using the actual Au electrode surface area because of the non-homogeneous distribution of the AuNPs on the GC electrode surface. Thus, the current density was based on the geometrical surface area. The upper potential limit was chosen 1.4 V in order to minimize the anodic dissolution of $\mathrm{Au}$ while 
Fig. 3 Last of the 30 consecutive cyclic voltammograms recorded in a $0.5-\mathrm{M} \mathrm{H}_{2} \mathrm{SO}_{4}$ solution on $\mathrm{AuNPs}(\mathrm{X})-\mathrm{GC}$ electrodes. (a) $\mathrm{X}=\mathrm{A} ;(b) \mathrm{X}=\mathrm{B} ;(c) \mathrm{X}=\mathrm{C} ;(d)$ $\mathrm{X}=\mathrm{D}$. Scan rate $100 \mathrm{mV} \mathrm{s}^{-1}$

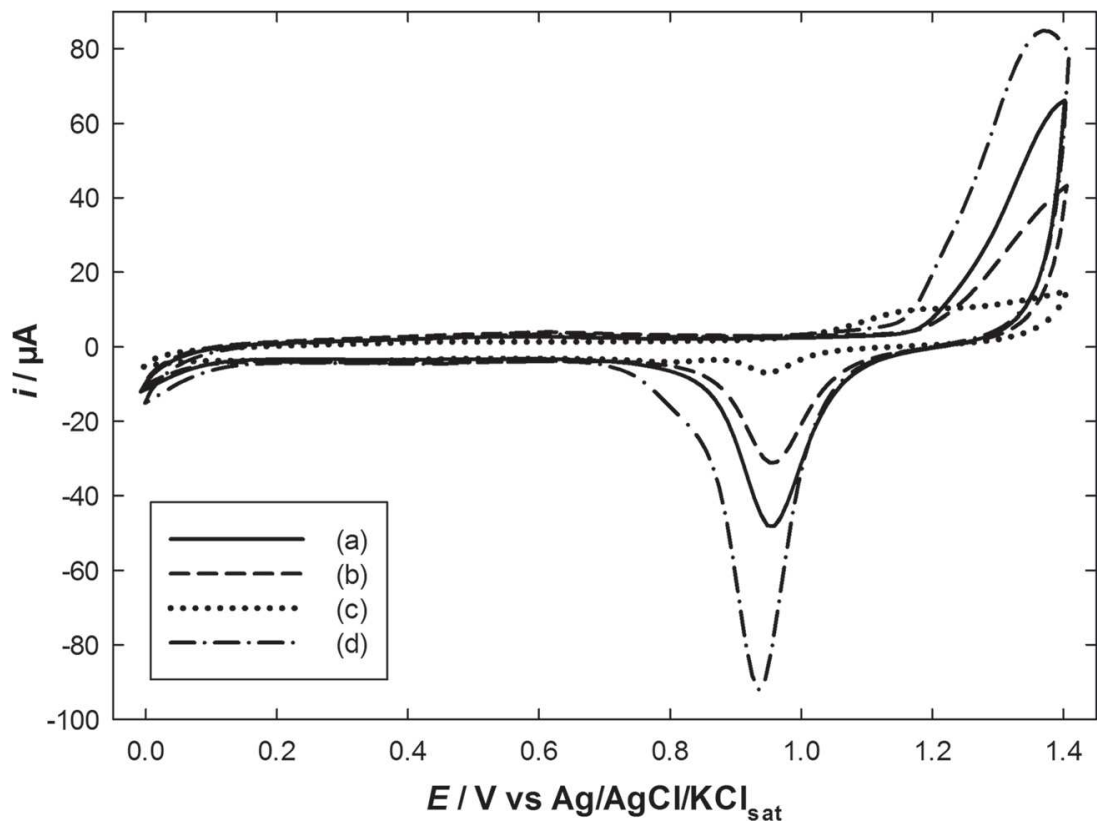

allowing $\mathrm{Au}$ oxide formation and subsequent AuNP activation, in accordance with recently published work [60, 61]. For all four deposits, the consecutive CVs were found to evolve in a similar way, with oxidation and reduction signals that increased during the first 20 scans and then remained nearly constant. All four last CVs exhibited the typical shape of $\mathrm{Au}$ electrochemical activation, i.e., oxidation of Au surface atoms to $\mathrm{Au}$ oxides at potentials higher than $1 \mathrm{~V}$ and subsequent reduction on the backward scan around $0.9 \mathrm{~V}$. The corresponding amounts of charge $Q_{\text {oxides }}$ are indicated in Table 1 . These data were found to be in good agreement with the AuNP deposits observed from FEG-SEM micrographs (Fig. 2 ). These values also compared well with that we previously reported for AuNPs electrodeposited by CPE which varied between 0.2 and $8.3 \mu \mathrm{C}$ depending on electrolysis potential and duration [44]. It has to be noticed that AuNPs(D)-GC electrode exhibited a $Q_{\text {oxides }}$ value $40 \%$ higher than the highest one reported in this previous work, thus suggesting a higher active surface area in the present case. The reason for the results obtained in the case of $\operatorname{AuNPs}(\mathrm{C})$ still remains unclear to us. Both synthesis $\mathrm{C}$ and the corresponding AuNP deposition onto GC electrode were reproduced several times, always leading to similar results. However, the CV corresponding to $\operatorname{AuNPs}(\mathrm{C})$ activation (Fig. 3, curve (c)) was consistent with Fig. 2c, confirming that very few NPs were deposited on the GC surface in this case.

\section{Kinetic study of ORR on AuNPs(X)-GC electrodes}

Steady-state voltammograms were recorded on each AuNPs(X)-GC electrode in an aerated NaCl-NaHCO (0.15 M/0.028 M, pH 7.4) solution (Fig. 4). This medium was chosen because it is very close to human blood ionic composition [62]. In such a neutral medium, the two consecutive two-electron reduction steps of $\mathrm{O}_{2}$ (Reactions 2 and 3) were observed on each electrode with roughly the same global current. However, in the case of $\operatorname{AuNPs}(\mathrm{B})-\mathrm{GC}$ and AuNPs(C)-GC, both waves were ill-defined and barely separated. On the latter electrode, the ORR kinetic seemed to be particularly slow, especially the first reaction step which concerned $\mathrm{O}_{2}$ reduction into $\mathrm{H}_{2} \mathrm{O}_{2}$. On the contrary, AuNPs(A)GC and AuNPs(D)-GC exhibited well-separated waves at nearly the same half-wave potentials, ca. -0.31 and $-0.81 \mathrm{~V}$ for $\mathrm{O}_{2}$ and $\mathrm{H}_{2} \mathrm{O}_{2}$ reduction, respectively. The fact that the two reduction processes occurred at the same potentials on both electrodes although the NP diameters were drastically different (ca. $18 \pm 4$ and $2 \pm 1 \mathrm{~nm}$ for $\operatorname{AuNPs}(\mathrm{A})$ and $\operatorname{AuNPs}(\mathrm{D})$, respectively) is surprising taking into account that the commonly reported trend is the smaller the NPs, the lower the cathodic overpotential [23, 41, 44]. However, it has to be noticed that the $\mathrm{NaCl}-\mathrm{NaHCO}_{3}$ media used to perform the voltammograms exhibited a low buffer capacity. Thus, large local $\mathrm{pH}$ variations may be expected close to the electrode surface and probably in a great part of the diffusion layer, which may account for the recorded half-wave potentials. NP coverage over the GC surface may also affect the ORR potential, but no particular trend was found here due to the lack of homogeneity of the deposits, except that of AuNPs(D). The half-wave potential values were very close to that reported for AuNPs electrodeposited onto GC by CPE at $-0.3 \mathrm{~V}$ for $1800 \mathrm{~s}$, which were -0.32 and $-0.82 \mathrm{~V}$ for $\mathrm{O}_{2}$ and $\mathrm{H}_{2} \mathrm{O}_{2}$ reduction, respectively [44]. With respect to what was observed on bulk Au [44, 45], AuNPs(A)-GC and AuNPs(D)GC electrodes afforded better selectivity for the two 
Fig. 4 Steady-state voltammograms recorded in an aerated $\mathrm{NaCl}-\mathrm{NaHCO}_{3}(0.15 \mathrm{M} /$ $0.028 \mathrm{M}, \mathrm{pH} 7.4)$ solution on $\operatorname{AuNPs}(\mathrm{X})-\mathrm{GC}$ electrodes: $(a)$ $\mathrm{X}=\mathrm{A} ;(b) \mathrm{X}=\mathrm{B} ;(c) \mathrm{X}=\mathrm{C} ;(d)$ $\mathrm{X}=\mathrm{D} ;(e)$ unmodified GC. Scan rate $1 \mathrm{mV} \mathrm{s}^{-1}$. Electrode rotation rate $1400 \mathrm{rpm}$

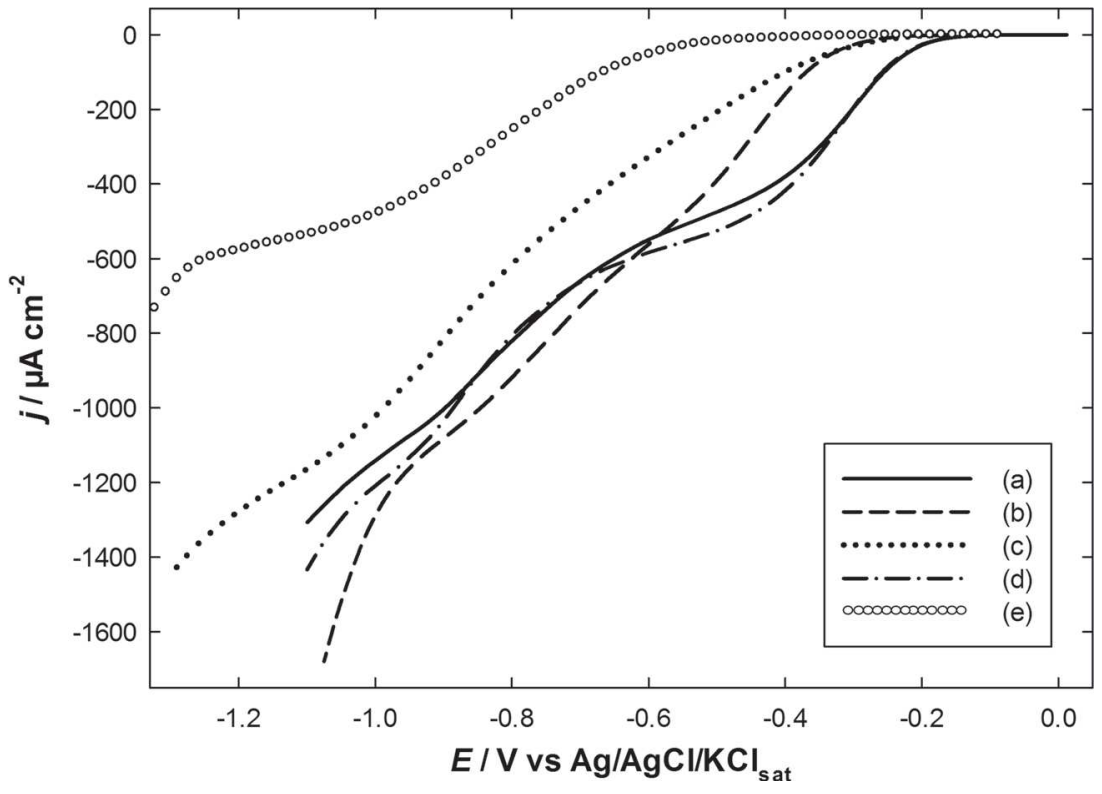

consecutive steps of ORR. The current densities corresponding to the mass-transfer-limited domain for both reduction processes were found to be slightly higher on $\operatorname{AuNPs}(\mathrm{D})$ GC than on AuNPs(A)-GC electrode, in accordance with the fact that small NPs are more reactive than big ones toward ORR. It has to be noticed that in the corresponding potential range, the substrate contribution to the first oxygen reduction wave was negligible (Fig. 4, curve (e)).

To go further into detail upon ORR kinetic features, steadystate voltammograms were recorded on $\operatorname{AuNPs}(\mathrm{X})-\mathrm{GC}$ electrodes at various rotation rates $\Omega$ (Fig. 5a). For the sake of clarity, only the results obtained on AuNPs(D)-GC were depicted. Starting from the open circuit potential (ocp) value and down to the early stages of oxygen first reduction wave, the recorded current densities were found to be independent on the value of $\Omega$, as the consequence of a charge-transferlimited reaction rate. At lower potential values, the cathodic current densities increased with a trend proportional to $\Omega^{1 / 2}$ (not shown), in accordance with the Levich equation. However, the current density plateau for the $\mathrm{O}_{2}$ reduction wave, which corresponded to mass transfer limitation, was poorly defined, thus indicating a mixed kinetic-diffusion control mechanism for the ORR. These observations compared favorably with our previous results obtained both on bulk $\mathrm{Au}$ [45] and on AuNPs prepared by electrochemical route using CPE [44]. The data recorded for each AuNPs(X)-GC electrode were treated using the Koutecky-Levich equation (Eq. (5)) [63]:

$\frac{1}{j}=\frac{1}{j_{\mathrm{k}}}+\frac{1}{j_{\mathrm{d}}}=-\frac{1}{n F k c}-\frac{1}{0.62 n F D^{2 / 3} \omega^{1 / 2} \nu^{-1 / 6} c}$

where $j_{\mathrm{k}}$ and $j_{\mathrm{d}}$ stand for the kinetic-limited and mass-transfercontrolled current densities, respectively, $F$ is the Faraday constant $\left(96,500 \mathrm{C} \mathrm{mol}^{-1}\right), k$ is the potential-dependent charge transfer rate constant, $c$ is the dioxygen bulk concentration $\left(0.24 \times 10^{-6} \mathrm{~mol} \mathrm{~cm}{ }^{-3}\right.$ under atmospheric pressure $)$ [64], D is the $\mathrm{O}_{2}$ diffusion coefficient $\left(1.96 \times 10^{-5} \mathrm{~cm}^{2} \mathrm{~s}^{-1}\right)[65,66]$, and $\nu$ is the kinematic viscosity of the aqueous solution $\left(0.01 \mathrm{~cm}^{2} \mathrm{~s}^{-1}\right)$ [67]. According to this equation, the inverse of the current density $1 / j$ was plotted as a function of $1 / \Omega^{1 / 2}$ for several potential values in the range from -0.2 to $-0.9 \mathrm{~V}$. Figure $5 b$ provides the results for AuNPs(D)-GC as an example. All the obtained curves exhibited a linear trend, from the slope of which the number of electrons exchanged $n$ during the ORR process was extracted. Figure $5 \mathrm{c}$ depicts the results obtained in the case of AuNPs(D)-GC electrode. In the potential range from -0.35 to $-0.65 \mathrm{~V}$, the $n$ value was roughly 2 in accordance with the bielectronic reduction of $\mathrm{O}_{2}$ into $\mathrm{H}_{2} \mathrm{O}_{2}$ (Reaction (2)). For potentials less cathodic than $-0.3 \mathrm{~V}$, the $n<2$ values did not have any physical meaning but only resulted from the mathematical treatment, showing that this potential range was far from the mass-transfer-limited region. Beyond $-0.65 \mathrm{~V}$, the $n$ value increased progressively up to 4 around $-1 \mathrm{~V}$ as the result of the complete reduction of $\mathrm{O}_{2}$ into $\mathrm{H}_{2} \mathrm{O}$ (Reaction (1)). This evolution of $n$ on AuNPs(D)-GC electrode compared favorably with that previously reported for AuNPs prepared by CPE at $-0.3 \mathrm{~V}$ for $1800 \mathrm{~s}$ (ca. $0.61 \pm 0.03)$ [44].

From the intercepts of the linear curves in Fig. 5b, the kinetic-limited current density contribution $j_{\mathrm{k}}$ was extracted and $\ln j_{\mathrm{k}}$ was plotted as a function of the potential (Fig. $5 \mathrm{~d}$ ). This allowed the cathodic transfer coefficient $\beta$ to be calculated from the charge transfer rate constant $k$ (Eq. (6)):

$k=k^{\circ} \exp \left(-\frac{\beta \mathrm{F}}{R T}\left(E-E^{\circ^{\prime}}\right)\right)$ 

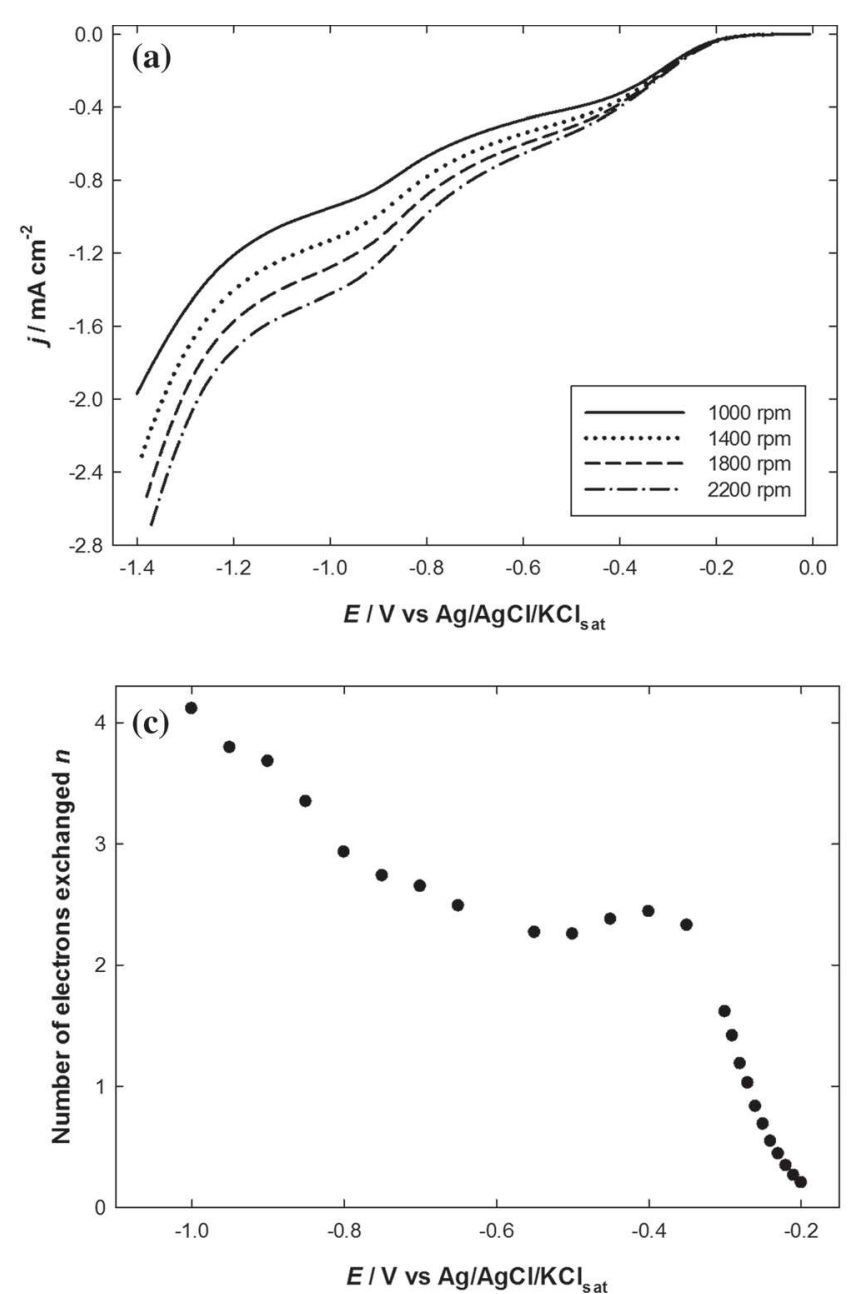

Fig. 5 a Steady-state voltammograms recorded on AuNPs(D)-GC electrode in an aerated $\mathrm{NaCl}-\mathrm{NaHCO}_{3}(0.15 \mathrm{M} / 0.028 \mathrm{M}, \mathrm{pH}$ 7.4) solution using various electrode rotation rates $\Omega$. Scan rate $1 \mathrm{mV} \mathrm{s}^{-1}$. b KouteckyLevich plots at different potentials ( $\mathrm{V}$ vs. $\mathrm{Ag} / \mathrm{AgCl} / \mathrm{KCl}_{\text {sat }}$ ) extracted from a. $\mathbf{c}$ Variation of the number of electrons $n$ exchanged during the ORR as a

where $k^{\circ}\left(\mathrm{cm} \mathrm{s}^{-1}\right)$ is the intrinsic charge transfer rate constant, $R$ is the gas constant $\left(8.31 \mathrm{~J} \mathrm{~mol}^{-1} \mathrm{~K}^{-1}\right)$, and $E^{\circ \prime}$ is the apparent standard potential (V). The $\beta$ values obtained on each AuNPs(X)-GC electrode are summarized in Table 1. These latter values clearly showed the better kinetics observed for the ORR on AuNPs(A)-GC and AuNPs(D)-GC compared to $\operatorname{AuNPs}(\mathrm{B})-\mathrm{GC}$ and $\operatorname{AuNPs}(\mathrm{C})-\mathrm{GC}$. The very low $\beta$ value obtained for AuNPs(B)-GC may be accounted for considering AuNPs(B) poor stability as proved by the corresponding $\zeta$ value that may disadvantage their interactions with the GC surface and, thus, slow down the electron transfer. As previously said in $\S 3.2$, the reason for the results obtained in the case of $\operatorname{AuNPs}(\mathrm{C})$ still remained unclear. The values obtained for AuNPs(A)-GC and AuNPs(D)-GC electrodes compared well with that previously reported for AuNPs prepared by $\mathrm{CPE}$ at $-0.3 \mathrm{~V}$ for $1800 \mathrm{~s}$ (ca. $0.61 \pm 0.03$ ) [44]. It has to be noticed that, although being the smallest ones, AuNPs(D) did not give rise to the best kinetics for the ORR. Apart their size
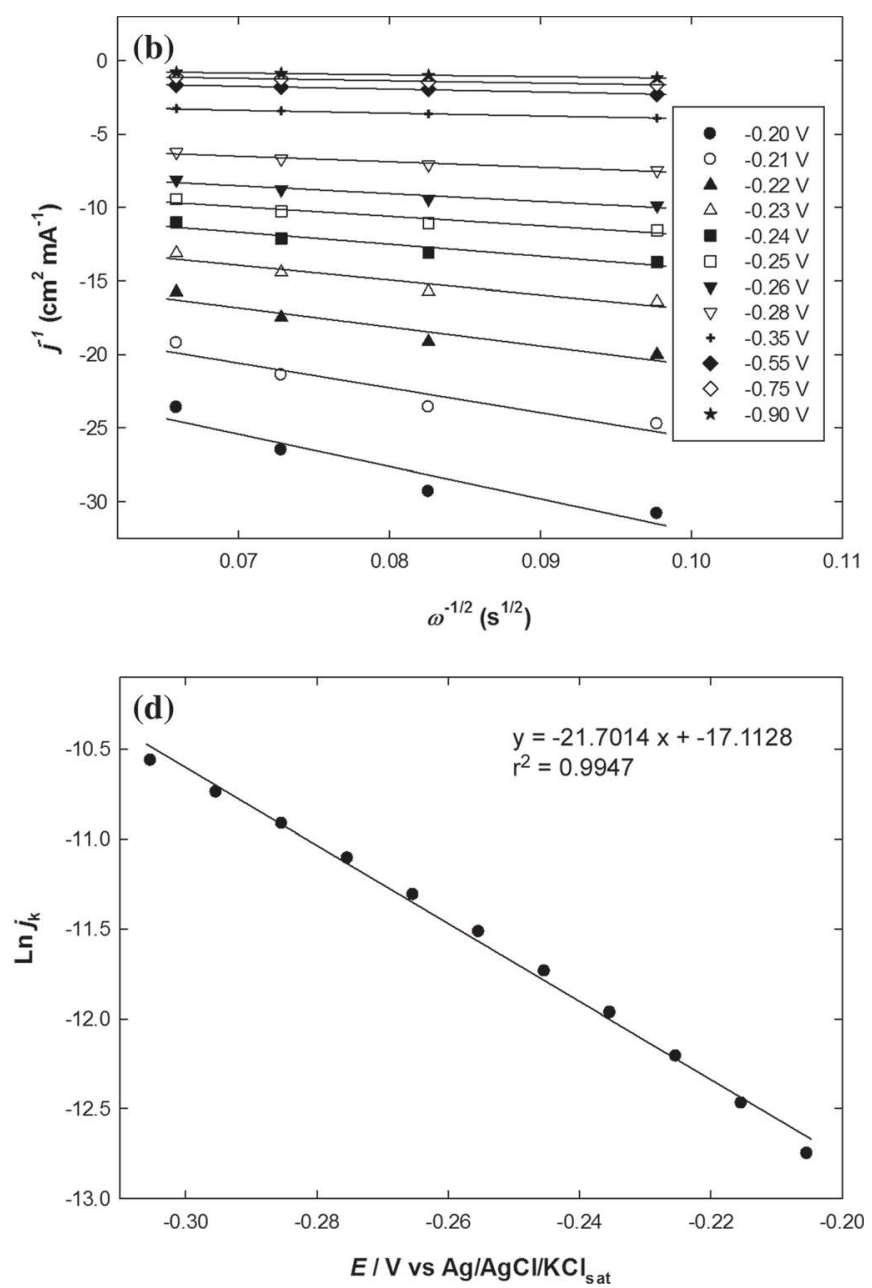

function of the electrode potential. Values extracted from the KouteckyLevich plot (b). d Variation of the kinetic-limited current density $\operatorname{Ln} j_{\mathrm{k}}$ of the ORR as a function of the applied potential. Values extracted from the Koutecky-Levich plot (b) and Eqs. (5) and (6)

and density, AuNPs(A) and AuNPs(D) differed by their ligand, since they bore citrate and NAC, respectively. The corresponding deposits onto the GC surface also exhibited very different morphologies. Thus, these results suggested that NP size is not the only factor that may impact ORR kinetic and illustrated the influence of the deposit morphology and the AuNP capping ligand. This latter is consistent with Mirkhalaf and Schiffrin's work which showed that the capping ligand influenced the ORR mechanism by modifying the local environment at the reaction centers [68]. The group of Garsany also evidenced a ligand effect in the case of PtNPs and proposed a weakening of the $\mathrm{Pt}-\mathrm{O}$ bond strength to account for it [69]. However, to the best of our knowledge, this is the first time such an influence combining ligand and deposit morphology effects is reported with respect to ORR in neutral media, the previous studies on ORR kinetic as a function of AuNP size being all conducted on NPs bearing a same or no ligand and in acidic or basic media $[23,44]$. Here, it may be 
assumed that NAC slowed down the electron transfer compared to citrate, probably because of its stronger interaction with Au: thus, although being much smaller than AuNPs(A), AuNPs(D) exhibited similar kinetic features. Further studies will be necessary to better understand the impact of the AuNP capping ligand and the NP deposit morphology on ORR kinetic.

\section{Conclusions}

In this work, colloidal AuNPs were prepared using four different chemical routes, affording a set of NPs with an average size from $2 \pm 1$ to $23 \pm 6 \mathrm{~nm}$. All the AuNPs were characterized using TEM images, UV-visible spectroscopy, and zeta potential measurements and then deposited by drop casting onto GC electrodes. All the deposits were tested with respect to the ORR in an aerated $\mathrm{NaCl}-\mathrm{NaHCO}_{3}(0.15 \mathrm{M} / 0.028 \mathrm{M}$, $\mathrm{pH}$ 7.4) neutral solution. All the AuNPs-GC electrodes exhibited a consecutive two-bielectronic-step mechanism for $\mathrm{O}_{2}$ reduction. However, only AuNPs(A)-GC and AuNPs(D)-GC showed well-separated waves for these two steps. From the Koutecky-Levich treatment of the steady-state current-potential curves, the values of the cathodic transfer coefficient $\beta$ were extracted and found to be $0.59 \pm 0.04$ and $0.55 \pm 0.04$ for AuNPs(A)-GC and AuNPs(D)-GC, respectively. These values compared well with that reported for AuNPs prepared by $\mathrm{CPE}$ at $-0.3 \mathrm{~V}$ for $1800 \mathrm{~s}$ (ca. $0.61 \pm 0.03$ ). The fact that AuNPs(A) and AuNPs(D), which used citrate and NAC as the stabilizing agents, respectively, lead to quite similar $\beta$ values suggested that the capping ligand of the NPs and the corresponding deposit morphology have an influence on ORR kinetic in neutral media. Further work is necessary to verify whether or not these results are applicable to various other organic ligands.

Acknowledgments The authors thank the Pôle de Recherche et de l'Enseignement Supérieur (PRES) Toulouse and the Région MidiPyrénées for financial support, Dr. Teddy Hezard for his help in MATLAB programming, and Sandrine Desclaux for $\zeta$ potential measurements. DE thanks Dr. Martine Meireles and Dr. Yannick Hallez for helpful discussion.

\section{References}

1. Song C, Zhang J (2008) Electrocatalytic oxygen reduction reaction. In: Zhang J (ed) PEM fuel cell electrocatalysts and catalyst layers. Springer, London

2. Keith JA, Jacob T (2010) Computational simulations on the oxygen reduction reaction in electrochemical systems. Mod Aspect Electroc 50:89-132

3. Koper MTM, Heering HA (2010) Comparison of electrocatalysis and bioelectrocatalysis of hydrogen and oxygen redox reactions. In:
Wieckowski A, Norskov JK (eds) Fuel cell science. Theory, fundamentals and biocatalysis. Wiley, Hoboken

4. Adzic R (1998) Recent advances in the kinetics of oxygen reduction. Wiley VCH, New York

5. Kazeman I, Hasanzadeh M, Jafarian M, Shadjou N, Khalilzadeh B (2010) Oxygen reduction reaction on a rotating Ag-GC disk electrode in acidic solution. Chin J Chem 28:504-508

6. Appleby AJ (1993) Electrocatalysis of aqueous dioxygen reduction. J Electroanal Chem 357:117-179

7. Damjanovic A, Brusic V, Bockris JOM (1967) Mechanism of oxygen reduction related to electronic structure of gold-palladium alloy. J Phys Chem 71:2741-2742

8. Sawyer DT, Chiericato G Jr, Angelis CT, Nanni EJ Jr, Tsuchiya T (1982) Effects of media and electrode materials on the electrochemical reduction of dioxygen. Anal Chem 54:1720-1724

9. Yeager E (1984) Electrocatalysts for molecular oxygen reduction. Electrochim Acta 29:1527-1537

10. Yeager E (1986) Dioxygen electrocatalysis. Mechanisms in relation to catalyst structure. J Mol Catal 38:5-25

11. Gnanamuthu DS, Petrocelli JV (1967) A generalized expression for the Tafel slope and the kinetics of oxygen reduction on noble metals and alloys. J Electrochem Soc 114:1036-1041

12. Sardar R, Funston AM, Mulvaney P, Murray RW (2009) Gold nanoparticles: past, present, and future. Langmuir 25:13840-13851

13. Sarapuu A, Nurmik M, Mändar H, Rosental A, Laaksonen T, Kontturi K, Schiffrin DJ, Tammeveski K (2008) Electrochemical reduction of oxygen on nanostructured gold electrodes. J Electroanal Chem 612:78-86

14. Dai X, Nekrassova O, Hyde ME, Compton RG (2004) Anodic stripping voltammetry of arsenic(III) using gold nanoparticlemodified electrodes. Anal Chem 76:5924-5929

15. Campbell FW, Compton RG (2010) The use of nanoparticles in electroanalysis: an updated review. Anal Bioanal Chem 396:241259

16. Mohanty US (2011) Electrodeposition: a versatile and inexpensive tool for the synthesis of nanoparticles, nanorods, nanowires, and nanoclusters of metals. J Appl Electrochem 41:257-270

17. Alexeyeva N, Tammeveski K (2008) Electroreduction of oxygen on gold nanoparticle/PDDA-MWCNT nanocomposites in acid solution. Anal Chim Acta 618:140-146

18. Zhao P, Li N, Astruc D (2013) State of the art in gold nanoparticle synthesis. Coord Chem Rev 257:638-665

19. El-Deab MS, Sotomura T, Ohsaka T (2005) Morphological selection of gold nanoparticles electrodeposited on various substrates. $\mathrm{J}$ Electrochem Soc 152:C730-C737

20. Erikson H, Sarapuu A, Tammeveski K, Solla-Gullon J, Feliu JM (2014) Shape-dependent electrocatalysis: oxygen reduction on carbon-supported gold nanoparticles. Chem Electro Chem 1: 1338-1347

21. Kuai L, Geng B, Wang S, Zhao Y, Luo Y, Jiang H (2011) Silver and gold icosahedra: one-pot water-based synthesis and their superior performance in the electrocatalysis for oxygen reduction reaction in alkaline media. Chemistry-A European J 17:3482-3489

22. Hernández J, Solla-Gullón J, Herrero E, Aldaz A, Feliu JM (2007) Electrochemistry of shape-controlled catalysts: oxygen reduction reaction on cubic gold nanoparticles. J Phys Chem C 111:1407814083

23. Inasaki T, Kobayashi S (2009) Particle size effects of gold on the kinetics of the oxygen reduction at chemically prepared $\mathrm{Au} / \mathrm{C}$ catalysts. Electrochim Acta 54:4893-4897

24. Schmidt TJ, Stamenkovic V, Arenz M, Markovic NM, Ross PN Jr (2002) Oxygen electrocatalysis in alkaline electrolyte: Pt(hkl), $\mathrm{Au}(\mathrm{hkl})$ and the effect of Pd-modification. Electrochim Acta 47: 3765-3776 
25. Hernández J, Solla-Gullón J, Herrero E, Feliu JM, Aldaz A (2009) In situ surface characterization and oxygen reduction reaction on shape-controlled gold nanoparticles. J Nanosci Nanotechnol 9: 2256-2273

26. El-Deab MS, Sotomura T, Ohsaka T (2005) Oxygen reduction at electrochemically deposited crystallographically oriented $\mathrm{Au}(100)$-like gold nanoparticles. Electrochem Commun 7:29-34

27. Wain AJ (2013) Imaging size effects on the electrocatalytic activity of gold nanoparticles using scanning electrochemical microscopy. Electrochim Acta 92:383-391

28. Štrbac S, Adžic RR (1996) The influence of $\mathrm{pH}$ on reaction pathways for $\mathrm{O}_{2}$ reduction on the $\mathrm{Au}(100)$ face. Electrochim Acta 41: 2903-2908

29. Blizanac BB, Lucas CA, Gallagher ME, Arenz M, Ross PN, Markovic NM (2004) Anion adsorption, CO oxidation, and oxygen reduction reaction on a $\mathrm{Au}(100)$ surface: the $\mathrm{pH}$ effect. J Phys Chem B 108:625-634

30. Mohammad AM, Awad MI, El-Deab MS, Okajima T, Ohsaka T (2008) Electrocatalysis by nanoparticles: optimization of the loading level and operating $\mathrm{pH}$ for the oxygen evolution at crystallographically oriented manganese oxide nanorods modified electrodes. Electrochim Acta 53:4351-4358

31. Rodriguez P, Koper MTM (2014) Electrocatalysis on gold. Phys Chem Chem Phys 16:13583-13594

32. Quaino P, Luque NB, Nazmutdinov R, Santos E, Schmickler W (2012) Why is gold such a good catalyst for oxygen reduction in alkaline media? Angew Chem, Int Ed Engl 51:12997-13000

33. Wang Y, Laborda E, Plowman BJ, Tschulik K, Ward KR, Palgrave RG, Dammd C, Compton RG (2014) The strong catalytic effect of $\mathrm{Pb}$ (II) on the oxygen reduction reaction on $5 \mathrm{~nm}$ gold nanoparticles. Phys Chem Chem Phys 16:3200-3208

34. El-Deab MS, Sotomura T, Ohsaka T (2006) Oxygen reduction at $\mathrm{Au}$ nanoparticles electrodeposited on different carbon substrates. Electrochim Acta 52:1792-1798

35. Vázquez-Huerta G, Ramos-Sánchez G, Antaño-López R, SolorzaFeria O (2009) Electrocatalysis of oxygen reduction on Au nanoparticles. ECS Trans 20:259-265

36. Vázquez-Huerta G, Ramos-Sánchez G, Rodríguez-Castellanos A, Meza-Calderón D, Antaño-López R, Solorza-Feria O (2010) Electrochemical analysis of the kinetics and mechanism of the oxygen reduction reaction on $\mathrm{Au}$ nanoparticles. J Electroanal Chem 645:35-40

37. Tang W, Lin H, Kleiman-Shwarsctein A, Stucky GD, McFarland EW (2008) Size-dependent activity of gold nanoparticles for oxygen electroreduction in alkaline electrolyte. J Phys Chem C 112: 10515-10519

38. Jirkovsky JS, Halasa M, Schiffrin DJ (2010) Kinetics of electrocatalytic reduction of oxygen and hydrogen peroxide on dispersed gold nanoparticles. Phys Chem Chem Phys 12:8042-8052

39. El-Deab MS, Okajima T, Ohsaka T (2003) Electrochemical reduction of oxygen on gold nanoparticle-electrodeposited glassy carbon electrodes. J Electrochem Soc 150:A851-A857

40. Raj CR, Abdelrahman AI, Ohsaka T (2005) Gold nanoparticleassisted electroreduction of oxygen. Electrochem Commun 7: 888-893

41. Shim JH, Kim J, Lee C, Lee Y (2011) Electrocatalytic activity of gold and gold nanoparticles improved by electrochemical pretreatment. J Phys Chem C 115:305-309

42. Skwierawski A (2013) The use of the integrated trophic state index in evaluation of the restored shallow water bodies. Ecol Chem Eng A 20:1275-1283

43. Hahn CEW (1998) Electrochemical analysis of clinical blood-gases, gases and vapors. Analyst 123:57R-86R

44. Gotti G, Fajerwerg K, Evrard D, Gros P (2014) Electrodeposited gold nanoparticles on glassy carbon: correlation between nanoparticles characteristics and oxygen reduction kinetics in neutral media. Electrochim Acta 128:412-419

45. Gotti G, Fajerwerg K, Evrard D, Gros P (2013) Kinetics of dioxygen reduction on gold and glassy carbon electrodes in neutral media. Int J Electrochem Sci 8:12643-12657

46. Turkevich J, Stevenson PC, Hillier J (1951) A study of the nucleation and growth processes in the synthesis of colloidal gold. Discuss Faraday Soc 11:55-75

47. Frens G (1973) Controlled nucleation for the regulation of the particle size in monodisperse gold suspensions. Nature (London). Physical Science 241:20-22

48. Smoluchowski MV (1903) Contribution to the theory of electroosmosis and related phenomena. Bull Int Acad Sci Cracovie 3:184199

49. Wiersema PH, Loeb AL, Overbeek JTG (1966) calculation of the electrophoretic mobility of a spherical colloidal particle. J Colloid Interface Sci 22:78-99

50. Turkevich J (1985) Colloidal gold. Part I. Historical and preparative aspects, morphology and structure. Gold Bull 18:8691

51. Su H, Zheng Q, Li H (2012) Colorimetric detection and separation of chiral tyrosine based on $\mathrm{N}$-acetyl-L-cysteine modified gold nanoparticles. J Mater Chem 22:6546-6548

52. Farrag M, Tschurl M, Heiz U (2013) Chiral gold and silver nanoclusters: preparation, size selection, and chiroptical properties. Chem Mater 25:862-870

53. Link S, El-Sayed MA (1999) Size and temperature dependence of the plasmon absorption of colloidal gold nanoparticles. J Phys Chem B 103:4212-4217

54. Majzik A, Patakfalvi R, Hornok V, Dékány I (2009) Growing and stability of gold nanoparticles and their functionalization by cysteine. Gold Bull 42:113-123

55. Brewer SH, Glomm WR, Johnson MC, Knag MK, Franzen S (2005) Probing BSA binding to citrate-coated gold nanoparticles and surfaces. Langmuir 21:9303-9307

56. Jin R, Zhu Y, Qian H (2011) Quantum-sized gold nanoclusters: bridging the gap between organometallics and nanocrystals. Chemistry-A European J 17:6584-6593

57. Mocanu A, Cernica I, Tomoaia G, Bobos L-D, Horovitz O, Tomoaia-Cotisel M (2009) Self-assembly characteristics of gold nanoparticles in the presence of cysteine. Colloids Surf A Physicochem Eng Asp 338:93-101

58. Hunter RJ (1981) Zeta potential in colloid science: principles and applications. Academic Press, London, UK

59. Jungers JC, Sajus L, de Aguirre I, Decroocq D (1968) L'analyse cinétique de la transformation chimique, Tome 2. Publications de l'Institut Français du Pétrole, Technip, Paris

60. Steven JT, Golovko VB, Johannessen B, Marshall AT (2016) Electrochemical stability of carbon-supported gold nanoparticles in acidic electrolyte during cyclic voltammetry. Electrochim Acta 187:593-604

61. Cruickshank AC, Downard AJ (2009) Electrochemical stability of citrate-capped gold nanoparticles electrostatically assembled on amine-modified glassy carbon. Electrochim Acta 54:5566-5570

62. Hendry EB (1962) The osmotic pressure and chemical composition of human body fluids. Human Body Fluids 8:246265

63. Koutecky J (1953) Kinetics of electrode processes. XI The polarographic current due to an electrode process preceded by a chemical reaction in solution between reactants differing in their diffusion coefficients. Chemicke Listy pro Vedu a Prumysl 47:1758-1761

64. Benson BB, Krause DJ (1984) The concentration and isotopic fractionation of oxygen dissolved in freshwater and 
seawater in equilibrium with the atmosphere. Limnol Oceanogr 29:620-632

65. van Stroe AJ, Janssen LJJ (1993) Determination of the diffusion coefficient of oxygen in sodium chloride solutions with a transient pulse technique. Anal Chim Acta 279:213-219

66. Jamnongwong M, Loubiere K, Dietrich N, Hebrard G (2010) Experimental study of oxygen diffusion coefficients in clean water containing salt, glucose or surfactant: consequences on the liquid-side mass transfer coefficients. Chem Eng J 165: $758-768$
67. Millero FJ, Huang F, Laferiere AL (2002) Solubility of oxygen in the major sea salts as a function of concentration and temperature. Mar Chem 78:217-230

68. Mirkhalaf F, Schiffrin DJ (2010) Electrocatalytic oxygen reduction on functionalized gold nanoparticles incorporated in a hydrophobic environment. Langmuir 26:14995-15001

69. Pietron JJ, Garsany Y, Baturina O, Swider-Lyons KE, Schull TL (2007) Electrochemical observation of ligand effects on oxygen reduction at ligand-stabilized Pt nanoparticle electrocatalysts. ECS Trans 11:217-226 